\title{
Parents with anxiety disorders
}

Book or Report Section

Accepted Version

Creswell, C., Cooper, P. J. and Murray, L. (2015) Parents with anxiety disorders. In: Reupert, A., Maybery, D., Nicolson, J., Gopfert, M. and Seeman, M. V. (eds.) Parental Psychiatric Disorder: Distressed parents and their families. Cambridge University Press, pp. 127-137. ISBN 9781107070684 Available at http://centaur.reading.ac.uk/58181/

It is advisable to refer to the publisher's version if you intend to cite from the work. See Guidance on citing.

Publisher: Cambridge University Press

All outputs in CentAUR are protected by Intellectual Property Rights law, including copyright law. Copyright and IPR is retained by the creators or other copyright holders. Terms and conditions for use of this material are defined in the End User Agreement. 


\section{CentAUR}

Central Archive at the University of Reading

Reading's research outputs online 


\author{
Parents with Anxiety Disorders \\ Dr Cathy Creswell ${ }^{1 *}$, Prof Peter J Cooper ${ }^{2}$, Prof Lynne Murray ${ }^{2}$ \\ ${ }^{1}$ University of Reading, ${ }^{2}$ University of Reading/ Stellenbosch University
}

School of Psychology and Clinical Language Sciences, University of Reading, Reading,

Berkshire, RG6 6AL, UK. E-mail: c.creswell@ reading.ac.uk, Telephone: +44 1183786798 , 


\section{Parents with Anxiety Disorders}

‘Anxiety Disorders' (ADs) are a broad category of psychiatric disorders characterized by excessive fear, worry or anxiety which cause significant distress or impairment in everyday life. They are among the most common psychiatric disorders, affecting over a quarter of people during their lifetime (Ronald C. Kessler et al., 2005). This chapter reviews the evidence concerning the psychological mechanisms by which ADs affect parenting and adjustment in children and young people, in order to guide further research in this area and inform clinical practice.

Most research in this field has focused on the impact of maternal ADs on parenting and children's development, largely because women are at higher risk of ADs than men (e.g. Ronald C. Kessler et al., 2005) and tend to be the primary caretakers of children in Western cultures. Nevertheless, recent studies including fathers with ADs have found similar associations between parenting and child adjustment to those found with mothers with ADs (Aktar, Majdandžić, de Vente, \& Bögels, 2013, 2014). Thus, in the absence of evidence to the contrary, it would be prudent to assume that studies of 'mothers' may well provide evidence relating to 'parents'. However, we also consider potential gender-specific associations with parenting and child adjustment when appropriate.

\section{Outcomes for children of parents with anxiety disorders}

Offspring of parents with ADs are(e.g. Beidel \& Turner, 1997; K. R. Merikangas, Avenevoli, Dierker, \& Grillon, 1999). Specifically, these offspring have a four-fold risk of AD compared to 
offspring of parents with no psychiatric diagnoses, and two-fold risk compared to offspring of parents with other psychiatric (non-anxiety) disorders (Micco et al., 2009). Offspring of parents with AD may also be at somewhat increased risk for mood disorders, particularly where parents have comorbid mood disorders (Micco et al., 2009).

Most studies examining outcomes of the offspring of parents with AD have included parents with a heterogeneous group of ADs, but there is evidence for specific associations between particular parent and child diagnoses in the case of Panic Disorder (Joseph Biederman et al., 2001; J Biederman et al., 2004; Unnewehr, Schneider, Florin, Margraf, \& rgen, 1998), social AD (Lieb et al., 2000), and specific phobias (Unnewehr et al., 1998). Of note, however, studies have typically included children from broad age-ranges (e.g. 2 to 25 years), which is problematic as different ADs tend to occur at different ages (Ronald C. Kessler et al., 2005), and one AD may be a precursor to another (e.g. (Joseph Biederman et al., 2007). To overcome this difficulty, in the Reading longitudinal study we recruited mothers with social AD ( $\mathrm{n}=96)$, generalized AD (n $=58)$, or with no history of an $\mathrm{AD}(\mathrm{n}=94)$ during pregnancy. Families were then followed up as the children reached particular ages (10 days, 10 weeks, 10, 14 and 24 months and 4-5 years), allowing direct comparisons between groups at critical points in the child's development. It is notable that at the most recent assessment (age 4-5 years) inflated levels of internalizing difficulties and social AD (15\%), specifically, were already apparent among the offspring of mothers with social AD compared to those with generalized AD (2\%) and those with no history of $\mathrm{AD}(0 \%)$ (L Murray et al., in press). These findings are consistent with the hypothesis that maternal $\mathrm{AD}$ presents a risk for the development of $\mathrm{AD}$ in offspring, and that there is early diagnostic-specificity in transmission, at least in the case of social AD. 


\section{Mechanisms of intergenerational transmission of anxiety}

In 2009 we proposed a model of pathways to the development of child anxiety which attempted to account for the fact that the risk of ADs is raised amongst offspring of parents with ADs (L. Murray, Creswell, \& Cooper, 2009). Specifically we suggested that key mechanisms in the development of child anxiety include (i) an anxious predisposition, (ii) socialization experiences (i.e. fewer opportunities to experience and develop skills in social environments or more negative social experiences), and (iii) learning via anxiogenic modelling and information transfer; and that all these factors are more likely in the context of parental AD. Furthermore, we suggested that highly anxious parents may be more likely to respond to their child's expressions of inhibition or anxiety with behaviours that reinforce child anxiety (e.g. lack of encouragement and intrusive or overprotective behaviours). This chapter provides an opportunity to reflect on the empirical status of the place of parental ADs within this model and consider future directions for research and practice.

\section{(i) Anxious predisposition}

Twin and adoption studies demonstrate that childhood anxiety is moderately heritable (Gregory \& Eley, 2007), although the magnitude of effects varies according to child sex, age, information source (i.e. parent vs child rated), as well as the form of anxiety. The genetic substrate of anxiety is poorly understood (e.g. Arbelle et al., 2003; Battaglia et al., 2005), yet is likely to differ in its effects in response to interactions with environmental characteristics (e.g. Caspi et al., 2003; Fox, Henderson, Marshall, Nichols, \& Ghera, 2005). The psychological trait most widely investigated as a potential vulnerability factor for the development of anxiety is Behavioral Inhibition $(\mathrm{BI})$ - i.e. the temperamental pattern characterized by fear and withdrawal in 
unfamiliar situations. BI is considered to be an early temperamental precursor of ADs, particularly social AD (e.g. Hirshfeld-Becker et al., 2008).

Studies of the degree to which parental ADs constitute a risk for BI among offspring have mostly been limited to those of parents with panic disorder and agoraphobia, and results have been mixed, with some suggesting that high rates of BI are accounted for by comorbidity with parental depression (Rosenbaum et al., 2000). In the Reading longitudinal study we found no significant difference in rates of high infant irritability at 10 weeks (L. Murray, Cooper, Creswell, Schofield, \& Sack, 2007) or (non-social) BI at 14 months of age (L. Murray et al., 2007) between infants of anxious and non-anxious mothers. Together these findings fail to show a clear link between early $\mathrm{BI}$ and parental $\mathrm{AD}$. Thus, reported associations between later $\mathrm{BI}$ and parental $\mathrm{ADs}$ may reflect offspring responses (e.g. to environmental influences associated with the parental disorder), or may occur as a result of comorbid parental conditions.

It has been suggested that biases of attention and interpretation may create a predisposition to the development of anxiety in children (J.L. Hudson \& Rapee, 2004; Ronald M Rapee \& Spence, 2004). Whether parental anxiety creates a risk for such biased information processing has received little examination, although there is some suggestion that offspring (9-19 years) of parents with panic disorder show distinctive attentional patterns to emotional stimuli that are not accounted for by child anxiety (Pine, et al., 2005). It is not clear whether these findings reflect genetic or environmental factors; however, our finding that 10 week old infants of mothers with social AD avoid high intensity fear faces (compared to offspring of mothers with Generalised Anxiety Disorder (GAD) and nonanxious mothers) does indicate that biases in the processing of 
emotional stimuli may be present from a very early age (C Creswell et al., 2011; C Creswell et al., 2008).

Together these lines of evidence highlight that, while children of parents with ADs are at an inflated risk for ADs, underlying vulnerability factors have not been clearly identified.

\section{(ii) Socialization experiences}

Exposure to negative life events may play a causal role in the development of ADs (e.g. Goodyer, Wright, \& Altham, 1988). Our model suggested that parental anxiety may be associated with increased exposure to particular negative life events, which could increase the risk of child anxiety, either directly or by diminishing the child's sense of control (L. Murray et al., 2009). There has been little research examining this proposition. However life events that are known to be more common amongst adults with ADs (e.g. Ronald C Kessler, Walters, \& Forthofer, 1998; Kathleen R Merikangas et al., 1998), have been found to be associated with ADs in offspring, e.g. marital breakdown (Shanahan, Copeland, Costello, \& Angold, 2008).

Further, in line with suggestions by (R.M. Rapee \& Heimberg, 1997), we suggested that anxious parents may, as a function of their own disorder, place limits on their children's wider experiences which could inflate apprehension, reduce opportunities to learn skills and develop independence, and create an over reliance on a limited number of adults. Again, little research has directly examined this proposal. In the Reading longitudinal study, the infants of mothers with social $\mathrm{AD}$ experienced less care-taking by people other than the mothers (including the father), and they were less likely to have attended non-parental group care at 10 and 14 months 
of age; this care-taking pattern was associated with infant sleep problems at two years, a potential marker of later emotional problems (C Creswell, Murray, \& Cooper, Unpublished). These preliminary findings suggest that the socialization practices of parents with AD may present a risk for child adjustment.

\section{(iii) Anxiogenic modelling and information transfer}

Learning accounts have emphasized two further, likely overlapping, routes for the development of anxiety: observation of others' anxiety (modelling or a vicarious acquisition), and receiving information regarding the threatening nature of the environment (i.e. informational acquisition) (e.g. Bandura, 1986; Rachman, 1990).

\section{(a) Modelling}

Experimental studies have provided evidence for a causal role of parental modelling of anxious responses on the development of child fearful behaviours (De Rosnay, Cooper, Tsigaras, \& Murray, 2006; Gerull \& Rapee, 2002; R. M. Rapee \& Szollos, 2002). It seems plausible to assume that children of anxious parents have increased opportunities for vicarious learning, due to the frequent expression of anxiety by their parents. Indeed, in the Reading longitudinal study (L. Murray et al., 2007), mothers with social AD compared to non-anxious mothers, exhibited significantly more anxiety, engaged less with a stranger, and were less encouraging of their child's interaction with the stranger. Mothers with social AD were also observed to express higher levels of anxiety within a social referencing paradigm at 10 months which itself predicted increased infant avoidance of a stranger four months later particularly among high BI infants (Murray, et al., 2008). Boys also appeared more vulnerable than girls to the effects of the mother's disorder. 
Aktar et al. (2013) recently administered a similar paradigm with 122 mothers and fathers (with social AD, other ADs, or no history of ADs) and their 12 month old infants. As in our study, parents with a prenatal diagnosis of social $\mathrm{AD}$ expressed more anxiety during the task than the non-socially anxious groups. Furthermore, parental expressed anxiety was associated with greater infant avoidance among moderate to high BI offspring. Notably, higher levels of parental expressed anxiety at 12 months by parents with social AD and comorbid ADs (the most severe group) predicted offspring fear and avoidance at 30 months (Aktar, et al., 2014). The authors suggest that for offspring of severely socially anxious parents, anxious responses to social challenge may arise on the basis of their parents' behaviour at a critical point in development around the end of the first year.

Further longitudinal follow-up of the children participating in these studies will be important to ascertain whether these factors constitute risk for the development of an AD in later life. Nonetheless, these findings provide strong support for the hypothesis that observed parental anxiety influences the development of childhood anxiety, and that this may be particularly the case in the context of pre-existing vulnerability (i.e. high BI).

\section{(b) Information transfer}

Observational studies of children with ADs in conversation with their parents support the view that parental narratives can be an important influence on the development of children's anxiety (e.g. Barrett, Rapee, Dadds, \& Ryan, 1996; B. F. Chorpita, Albano, A. M., \& Barlow, D. H. , 1996). Few studies have investigated whether highly anxious parents convey potentially 
anxiogenic information to their offspring. In a preliminary investigation, with 68 mother-child (7-15 years) pairs, classified according to presence or absence of maternal and child AD, mothers with ADs were observed to make more catastrophic comments in interaction with their child (Moore, Whaley, \& Sigman, 2004). We recently reported consistent findings from the Reading longitudinal study. About two months before the children started school, mother-child pairs were observed talking about the forthcoming transition to school, using a picture book as a prompt. Compared to mothers with no history of AD, mothers with social AD expressed significantly more threat attribution and lower encouragement. Furthermore, children whose mothers expressed more threat were more likely to meet diagnostic criteria for social AD four months later. Thus, children's exposure to negative information poses risks for child adjustment, and maternal social $\mathrm{AD}$ increases the likelihood of this occurring.

\section{(iv) Reinforcing responses to child anxious behaviours}

The parenting dimensions that have most commonly been implicated in the development of child ADs are parental control and negativity. Specifically, it has been proposed that a parent's excessive regulation of child behaviour, and discouragement of independence, is likely to (a) communicate to the child that the world is a dangerous and uncontrollable place (e.g. J.L. Hudson \& Rapee, 2004), and (b) militate against the child's developing a sense of competence and mastery, reinforcing avoidance of challenge (B. F. Chorpita \& Barlow, 1998; Parker, 1983). Cross-sectional and experimental studies have provided evidence to support this hypothesis (e.g. (McLeod, Wood, \& Weisz, 2007). Furthermore, parental negativity, or lack of warmth has been suggested to lead the child to believe that the environment is fundamentally hostile and threatening and that outcomes will be negative, thereby contributing to the development of a 
sense of low self-worth and competence (Parker, 1983). Findings have been inconsistent with regards this hypothesis (e.g. McLeod, et al., 2007).

A number of theorists have suggested that parental control (and possibly negativity) are likely mechanisms by which parental AD poses a risk for offspring adjustment. Specifically, highly anxious parents may be more likely to exert excessive control over their child because of their own heightened perception of threat in their own and their child's environment and their increased sensitivity to their child's distress (e.g. Ginsburg \& Schlossberg, 2002; J.L. Hudson \& Rapee, 2004). Parental anxiety has also been proposed to lead to increased negativity to the child as a function of the parent's limited sense of control over their child's anxious responses (e.g.J.L. Hudson \& Rapee, 2004). There is currently little support for these proposals. In a small study by (Whaley, Pinto, \& Sigman, 1999), maternal AD was associated with increased negativity and reduced autonomy granting, however in an expanded version of this study effects appeared to be accounted for by the presence of child, rather than parental anxiety (Moore et al., 2004). Other studies have similarly failed to find associations between parental AD and over-control or negativity (Becker \& Ginsburg, 2011; Gar \& Hudson, 2008; Ginsburg, Grover, \& Ialongo, 2005; McClure, Brennan, Hammen, \& Le Brocque, 2001; Turner, Beidel, Roberson-Nay, \& Tervo, 2003; Woodruff-Borden, Morrow, Bourland, \& Cambron, 2002); with some, instead, finding a lack of engagement among parents with AD (Turner et al., 2003). Overall, it appears that more involved or controlling behaviour are common parental responses to having an anxious child, which might reinforce child anxiety. Indeed, a recent meta-analysis revealed a weak association between parental anxiety and observations of control $(\mathrm{d}=.08$; Van Der Bruggen, Stams, \& 
Bögels, 2008), although, notably stronger associations were found depending on the aspect of parental control assessed and methodological features of the studies $(d=.25-.49)$.

It is, nonetheless, possible that infant or child inhibition may provoke particular parenting styles more readily among anxious, compared to non-anxious parents. For example, (Hirshfeld, Biederman, Brody, Faraone, \& Rosenbaum, 1997) found that maternal criticism of the child was a function of a significant interaction between child BI and maternal status: within the group of anxious mothers, $65 \%$ of those with inhibited children were critical compared to $18 \%$ of those with non-inhibited children. Similarly (L. Murray et al., 2008) found that mothers with social AD showed low levels of autonomy promotion (encouragement) to their infants to engage with a stranger only where the infant was behaviourally inhibited. Recent findings from our research clinic have provided consistent results. Eighty-eight children with ADs (7-12 years) were observed interacting with their mothers in a range of challenging tasks. Despite no observable differences in child anxiety and avoidance during the tasks, mothers who had an AD reported more negative expectations of their child and showed higher levels of intrusive and anxious behaviours, lower levels of warmth and exhibited a more negative interactive tone than mothers without ADs, particularly when their children appeared anxious during the task (Cathy Creswell, Apetroaia, Murray, \& Cooper, 2013).

Together these findings suggest that over-controlling and, possibly, negative responses may reflect a common response to parenting an anxious or inhibited child, and that these behaviours may be especially likely to arise in parents who are themselves prone to anxiety when their child is confronted by a challenge. Only a few studies have examined whether these problematic 
parenting behaviours arise in particular ADs and in particular contexts. Challacombe and Salkovskis (2009) found that both mothers with OCD and those with panic disorder were less warm and autonomy promoting than non-anxious mothers during discussion tasks, with no significant differences between the two disorders. However, disorder specific effects have been found in the case of parental social $\mathrm{AD}$, with socially anxious mothers exhibiting less warmth, more criticism, and more doubts about their child's competency than mothers with other (nonsocial) ADs specifically in situations that posed a specific challenge to anxious mothers' disorder (Lynne Murray et al., 2012). The context-dependency of potentially anxiogenic parental responses of anxious parents has also been supported by a recent study by Stein et al. (2012). Specifically, mothers with GAD, in comparison to a healthy control group, and, to some extent, a group of mothers with major depressive disorder, were found to exhibit reduced responsiveness and vocalization with their 10 month old infants after being primed to worry relative to their responses to a neutral prime,. These findings highlight the need for carefully selected paradigms when assessing parent-child interactions in the context of parental ADs.

\section{Implications for frameworks}

Our 2009 model proposed a number of mechanisms by which high parental anxiety may increase the risk of anxiety disorders in offspring. There is clearly still a lot of work to be done. For example, mechanisms of transmission of anxious predisposition remain unclear, and there has been little work to evaluate the role of potential socialization experiences. Nonetheless, experimental and prospective studies have supported key learning processes, such as modelling and information transfer. Finally, recent findings support the suggestion that anxiogenic parental 
responses (e.g. reduced encouragement of child autonomy) to child inhibition/anxiety may be more likely to occur in the context of parental AD.

Overall the available literature presents a picture which is consistent with Goodman and Gotlib (1999's)influential model of the intergenerational transmission of depression. Living with a parent with an $\mathrm{AD}$ appears to entail not only an inherited risk but it also increases exposure to potential environmental risk factors. Also consistent with Goodman and Gotlib's (1999) model, evidence supports a role of both parent (e.g. disorder, comorbidity, cognitions and behaviors) and child characteristics (e.g. BI, age) and their interactions). Other factors that warrant further consideration as moderators of intergenerational risk including child sex (De Rosnay et al., 2006), attachment status (L Murray et al., in press), and information processing (Pass, Arteche, Cooper, Creswell, \& Murray, 2012). Family socio-economic status may also moderate risk by its influence on severity of parental disorder, comorbidity, parenting responses, family disruption, and wider stressors (e.g. Beidel \& Turner, 1997; K. R. Merikangas et al., 1999). Few studies have considered the independent and interacting effects of behaviours by different parents. Fathers and mothers may exert similar influences on child fear learning in some situations (Aktar et al., 2013, 2014), but fathers' parenting behaviours may play a central role in challenging children beyond their comfort zones, enabling children to face fears and develop confidence in the face of challenge (Majdandžić, Möller, de Vente, Bögels, \& van den Boom, 2014). ADs in fathers may inhibit these challenging behaviours (Bögels, Bamelis, \& van der Bruggen, 2008). The presence of paternal AD has also been found to influence co-parenting responses, with fathers with ADs being more likely than non-anxious fathers to be negative and dominating in family conversations. Notably, partners of fathers with ADs were also more negative in family 
conversations (Majdandžić et al., 2014), highlighting parents' influences on each other's parenting responses.

The majority of studies to date have been limited by the inclusion of predominantly affluent families of non-minority ethnicity. However, the importance of considering cultural factors is emphasized by a recent study showing that different patterns of association between parenting behaviours and child anxiety occur in Italian and British families (Raudino et al., 2013). Similarly, the impact of poverty and unemployment have received little attention in this field but are likely to bring additional risks, through, for example, associations with parental depression, substance abuse, and family disruption (K. R. Merikangas et al., 1999).

As in Goodman and Gotlib's (1999) model, the multiple routes to the development of childhood $\mathrm{AD}$ and multiple moderators provide an explanation of why there is not a direct relationship between parent and child ADs. Nonetheless, a number of potential targets for preventing and treatment child anxiety in the context of parental anxiety disorders have been identified.

\section{Prevention of child anxiety in the context of parental anxiety disorder}

In the one study that set out to prevent ADs by targeting offspring of parents with ADs, (Ginsburg, 2009) randomized 40 children aged 7 to 12 years (who did not themselves have a current $\mathrm{AD}$ ) to a preventive intervention or a waitlist condition. The prevention programme involved 6-8 weekly sessions (plus three monthly boosters) delivered to parents, aimed at increasing children's strength and resilience, reducing potential risk/maintenance factors, and improving family understanding and communication. By the one year follow-up 30\% of children 
in the wait-list had developed an AD, compared to no children in the prevention group. These findings are encouraging though replication and further longer term follow-up is warranted.

Given the identification of particular mechanisms associated with intergenerational transmission of anxiety in infancy and early childhood (e.g. Aktar et al., 2013, 2014; L. Murray et al., 2007; L. Murray et al., 2008), preventive approaches that target parents of young children may well be warranted. As not all children with parents with ADs will develop ADs, better means to identify those at greatest risk will be essential for targeting preventive efforts.

\section{Treatment of child anxiety disorders in the context of parental anxiety disorders}

(Kennedy, Rapee, \& Edwards, 2009) identified 71 children aged 36 to 58 months at risk for the development of ADs by virtue of both parental $\mathrm{AD}$ and high $\mathrm{BI}$ (in fact all participating children met criteria for an AD). Parents were randomized to an early intervention programme or a 6 month waitlist control condition. The intervention included similar components to that of (Ginsburg, 2009), focusing on psychoeducation, parental behaviours, targeting maladaptive thoughts (of children and parents), and helping children and parents face fears. . At the 6 month follow-up $47 \%$ of children in the intervention condition were free of all AD diagnoses compared to only $7 \%$ in the waitlist control. The findings suggest that young children of parents with ADs who are highly inhibited and/or have an AD may benefit significantly from early intervention.

The rate of child recovery for school-aged children with ADs receiving CBT has been found to be halved when a parent also has an AD (Bodden et al., 2008; Jennifer L Hudson et al., 2013). Two studies examined whether delivering brief treatments to target parent anxiety might benefit child treatment outcome, one reporting a benefit in child outcomes (Cobham, Dadds, \& Spence, 
1998) and the other failing to find a benefit (Jennifer L Hudson et al., 2013). We recently completed a randomized controlled trial $(n=211)$ in which children $(7-12$ years $)$ with ADs whose mothers also had an $\mathrm{AD}$ received $\mathrm{CBT}$ with the addition of more intensive treatment to target maternal ADs or a nonspecific intervention (C Creswell et al., submitted).. We also examined whether supplementing child CBT with treatment focused on mother-child interactions would improve child treatment outcome. Good outcomes were achieved for both children and mothers across all three treatment conditions (60-74\% free of their primary diagnosis at one year followup). Although there were no significant differences between groups on any of the primary outcome measures, supplementing CBT with the treatment that targeted the mother-child interaction was found to be a cost-effective use of resources (C Creswell et al., submitted). Notably, although treating maternal anxiety conferred a benefit in terms of improvements in maternal anxiety, mothers in the other intervention groups had similar improvements in their own anxiety after their children had received CBT. This finding emphasizes the reciprocal relationship between parent and child ADs.

The intervention studies conducted to date highlight the potential benefit of prevention and early intervention targeting offspring of parents with ADs. Recent developments in our understanding of the intergenerational transmission of ADs suggest that treatments could be further improved by engaging both parents in order to address their independent and co- parenting responses. Furthermore treatment studies also need to specifically consider the developmental needs of adolescents and how parental anxiety may impact on critical parenting responses at that stage in development (Waite, Whittington, \& Creswell, 2014). Finally, given emerging evidence that there may be disorder specific parenting effects in disorder relevant contexts (Budinger, 
Drazdowski, \& Ginsburg, 2013; L. Murray et al., 2007), treatments effects may be enhanced by taking disorder specific approaches. 


\section{References}

Aktar, E., Majdandžić, M., de Vente, W., \& Bögels, S. M. (2013). The interplay between expressed parental anxiety and infant behavioural inhibition predicts infant avoidance in a social referencing paradigm. Journal of Child Psychology and Psychiatry, 54(2), 144156. doi:10.1111/j.1469-7610.2012.02601.x

Aktar, E., Majdandžić, M., de Vente, W., \& Bögels, S. M. (2014). Parental social anxiety disorder prospectively predicts toddlers' fear/avoidance in a social referencing paradigm. Journal of Child Psychology and Psychiatry, 55(1), 77-87. doi:10.1111/jcpp.12121

Arbelle, S., Benjamin, J., Golin, M., Kremer, I., Belmaker, R. H., \& Ebstein, R. P. (2003). Relation of shyness in grade school children to the genotype for the long form of the serotonin transporter promoter region polymorphism. American Journal of Psychiatry, 160(4), 671-676.

Bandura, A. (1986). Social foundations of thought and action: Englewood Cliffs, NJ Prentice Hall.

Barrett, P. M., Rapee, R. M., Dadds, M. M., \& Ryan, S. M. (1996). Family enhancement of cognitive style in anxious and aggressive children. Journal of Abnormal Child Psychology, 24(2), 187-203.

Battaglia, M., Ogliari, A., Zanoni, A., Citterio, A., Pozzoli, U., Giorda, R., . . Marino, C. (2005). Influence of the serotonin transporter promoter gene and shyness on children's cerebral responses to facial expressions. Archives of General Psychiatry, 62(1), 85-94.

Becker, K. D., \& Ginsburg, G. S. (2011). Maternal anxiety, behaviors, and expectations during a behavioral task: Relation to children's self-evaluations. Child Psychiatry and Human Development, 42(3), 320-333. 
Beidel, D. C., \& Turner, S. M. (1997). At risk for anxiety: I. Psychopathology in the offspring of anxious parents. Journal of the American Academy of Child \& Adolescent Psychiatry, $36(7), 918-924$.

Biederman, J., Faraone, S. V., Hirshfeld-Becker, D. R., Friedman, D., Robin, J. A., \& Rosenbaum, J. F. (2001). Patterns of psychopathology and dysfunction in high-risk children of parents with panic disorder and major depression. American Journal of Psychiatry, 158(1), 49-57.

Biederman, J., Petty, C., Faraone, S. V., Hirshfeld-Becker, D. R., Henin, A., Gilbert, J., \& Rosenbaum, J. (2004). Moderating effects of major depression on patterns of comorbidity in referred adults with panic disorder: A controlled study. Psychiatry Research, 126, 143149.

Biederman, J., Petty, C. R., Hirshfeld-Becker, D. R., Henin, A., Faraone, S. V., Fraire, M., .. . Rosenbaum, J. F. (2007). Developmental trajectories of anxiety disorders in offspring at high risk for panic disorder and major depression. Psychiatry Research, 153(3), 245-252.

Bodden, D., Bögels, S., Nauta, M., de Hann, E., Ringrose, J., Appelboom, C., \& Brinkman, K. (2008). Child versus family cognitive behavioural therapy in clinically anxious youth: An efficacy and partial effectiveness study. Journal of Clinical Child and Adolescent Psychology, 47(12), 1384-1394.

Bögels, S. M., Bamelis, L., \& van der Bruggen, C. (2008). Parental rearing as a function of parent's own, partner's, and child's anxiety status: fathers make the difference. Cognition and Emotion, 22(3), 522-538. 
Budinger, M. C., Drazdowski, T. K., \& Ginsburg, G. S. (2013). Anxiety-promoting parenting behaviors: a comparison of anxious parents with and without social anxiety disorder. Child Psychiatry and Human Development, 44(3), 412-418.

Caspi, A., Sugden, K., Moffitt, T. E., Taylor, A., Craig, I. W., Harrington, H., . . Braithwaite, A. (2003). Influence of life stress on depression: moderation by a polymorphism in the 5HTT gene. Science, 301(5631), 386-389.

Challacombe, F., \& Salkovskis, P. (2009). A preliminary investigation of the impact of maternal obsessive-compulsive disorder and panic disorder on parenting and children. Journal of Anxiety Disorders, 23(7), 848-857.

Chorpita, B. F., Albano, A. M., \& Barlow, D. H. . (1996). Cognitive processing in children: Relation to anxiety and family influences. Journal of Clinical Child Psychology. Journal of Clinical Child Psychology, 25, 170-176.

Chorpita, B. F., \& Barlow, D. (1998). The development of anxiety: The role of control in early environment. Psychology Bulletin, 124, 3-21.

Cobham, V. E., Dadds, M. R., \& Spence, S. H. (1998). The role of parental anxiety in the treatment of childhood anxiety. Journal of consulting and clinical psychology, 66(6), 893.

Creswell, C., Apetroaia, A., Murray, L., \& Cooper, P. (2013). Cognitive, affective, and behavioral characteristics of mothers with anxiety disorders in the context of child anxiety disorder. Journal of Abnormal Psychology, 122(1), 26.

Creswell, C., Cooper, P., Giannakakis, A., Schofield, E., Woolgar, M., \& Murray, L. (2011). Emotion processing in infancy: specificity in risk for social anxiety and associations with 
two year outcomes. Journal of Experimental Psychopathology, 2(4), 490-508. doi:10.5127/jep.018911

Creswell, C., Cruddace, S., Gerry, S., Gitau, R., McIntosh, E., Mollison, J., . . Cooper, P. J. (submitted). Treatment of childhood anxiety disorder in the context of maternal anxiety disorder: A randomised controlled trial. Health Technology Assessment Reports.

Creswell, C., Murray, L., \& Cooper, P. (Unpublished). Use of non-maternal care by mothers with social phobia:

comparisons with non-anxious mothers and associations with child outcomes.

Creswell, C., Woolgar, M., Cooper, P., Giannakakis, A., Schofield, E., Young, A. W., \& Murray, L. (2008). Processing of faces and emotional expressions in infants at risk of social phobia. . Cognition \& Emotion, 22(3), 437-458. doi:10.1080/02699930701872392

De Rosnay, M., Cooper, P. J., Tsigaras, N., \& Murray, L. (2006). Transmission of social anxiety from mother to infant: an experimental study using a social referencing paradigm. Behaviour Research and Therapy, 44, 1165-1175.

Fox, N. A., Henderson, H. A., Marshall, P. J., Nichols, K. E., \& Ghera, M. M. (2005). Behavioral inhibition: linking biology and behavior within a developmental framework. Annual Review of Psychology, 56, 235-262.

Gar, N. S., \& Hudson, J. L. (2008). An examination of the interactions between mothers and children with anxiety disorders. Behaviour Research and Therapy, 46(12), 1266-1274.

Gerull, F. C., \& Rapee, R. M. (2002). Mother knows best: Effects of maternal modelling on the acquisition of fear and avoidance behavior in toddlers. Behavior Research and Therapy, 40, 279-287. 
Ginsburg, G. S. (2009). The child anxiety prevention study: intervention model and primary outcomes. Journal of Consulting and Clinical Psychology, 77(3), 580.

Ginsburg, G. S., Grover, R. L., \& Ialongo, N. (2005). Parenting behaviors among anxious and non-anxious mothers: Relation with concurrent and long-term child outcomes. Child \& Family Behavior Therapy, 26(4), 23-41.

Ginsburg, G. S., \& Schlossberg, M. C. (2002). Family-based treatment of childhood anxiety disorders. International Review of Psychiatry, 14(2), 143-154.

Goodman, S. H., \& Gotlib, I. H. (1999). Risk for psychopathology in the children of depressed mothers: a developmental model for understanding mechanisms of transmission. Psychological Review, 106(3), 458.

Goodyer, I. M., Wright, C., \& Altham, P. M. E. (1988). Maternal adversity and recent stressful life events in anxious and depressed children. Journal of Child Psychology and Psychiatry, 29, 651-667.

Gregory, A. M., \& Eley, T. C. (2007). Genetic influences on anxiety in children: what we've learned and where we're heading. . Clinical Child and Family Psychology Review, 10, 199-212.

Hirshfeld-Becker, D. R., Micco, J., Henin, A., Bloomfield, A., Biederman, J., \& Rosenbaum, J. (2008). Behavioral inhibition. Depression and Anxiety, 25(4), 357-367.

Hirshfeld, D. R., Biederman, J., Brody, L., Faraone, S. V., \& Rosenbaum, J. F. (1997). Expressed emotion toward children with behavioral inhibition: Associations with maternal anxiety disorder. Journal of the American Academy of Child and Adolescent Psychiatry, 36(7), 910-917. 
Hudson, J. L., Newall, C., Rapee, R. M., Lyneham, H. J., Schniering, C. C., Wuthrich, V. M., .. . Gar, N. S. (2013). The impact of brief parental anxiety management on child anxiety treatment outcomes: a controlled trial. Journal of Clinical Child and Adolescent Psychology(ahead-of-print), 1-11.

Hudson, J. L., \& Rapee, R. M. (2004). From Anxious Temperament to Disorder: An Etiological Model. In R. G. Heimberg, C. L. Turk, \& D. S. Mennin (Eds.), Generalized anxiety disorder: Advances in research and practice (pp. 51-74). New York: Guilford Press.

Kennedy, S. J., Rapee, R. M., \& Edwards, S. L. (2009). A selective intervention program for inhibited preschool-aged children of parents with an anxiety disorder: effects on current anxiety disorders and temperament. Journal of the American Academy of Child and Adolescent Psychiatry, 48(6), 602-609.

Kessler, R. C., Berglund, P., Demler, O., Jin, R., Merikangas, K. R., \& Walters, E. E. (2005). Lifetime prevalence and age-of-onset distributions of DSM-IV disorders in the national comorbidity survey replication.(vol 62, pg 593, 2005). Archives of General Psychiatry, $62(7), 768$.

Kessler, R. C., Walters, E. E., \& Forthofer, M. S. (1998). The social consequences of psychiatric disorders, III: probability of marital stability. American Journal of Psychiatry, 155(8), 1092-1096.

Lieb, R., Wittchen, H.-U., Hofler, M., Fuetsch, M., Stein, M. B., \& Merikangas, K. R. (2000). Parental Psychopathology, Parenting Styles, and the Risk of Social Phobia in Offspring: A Prospective-Longitudinal Community Study. Archives of General Psychiatry, 57(9), 859-866. doi:10.1001/archpsyc.57.9.859 
Majdandžić, M., Möller, E. L., de Vente, W., Bögels, S. M., \& van den Boom, D. C. (2014).

Fathers' Challenging Parenting Behavior Prevents Social Anxiety Development in Their 4-Year-Old Children: A Longitudinal Observational Study. Journal of Abnormal Child Psychology, 42(2), 301-310.

McClure, E. B., Brennan, P. A., Hammen, C., \& Le Brocque, R. M. (2001). Parental anxiety disorders, child anxiety disorders, and the perceived parent-child relationship in an Australian high-risk sample. Journal of Abnormal Child Psychology, 29(1), 1-10.

McLeod, B. D., Wood, J. J., \& Weisz, J. R. (2007). Examining the association between parenting and childhood anxiety: A meta-analysis. Clinical Psychology Review, 27(2), 155-172.

Merikangas, K. R., Avenevoli, S., Dierker, L., \& Grillon, C. (1999). Vulnerability factors among children at risk for anxiety disorders. Biological Psychiatry, 46(11), 1523-1535. doi:10.1016/s0006-3223(99)00172-9

Merikangas, K. R., Mehta, R. L., Molnar, B. E., Walters, E. E., Swendsen, J. D., AguilarGaziola, S., . . Dewit, D. J. (1998). Comorbidity of substance use disorders with mood and anxiety disorders: results of the International Consortium in Psychiatric Epidemiology. Addictive Behaviors, 23(6), 893-907.

Micco, J. A., Henin, A., Mick, E., Kim, S., Hopkins, C. A., Biederman, J., \& Hirshfeld-Becker, D. R. (2009). Anxiety and depressive disorders in offspring at high risk for anxiety: A meta-analysis. Journal of Anxiety Disorders, 23(8), 1158-1164. doi:10.1016/j.janxdis.2009.07.021

Moore, P. S., Whaley, S. E., \& Sigman, M. (2004). Interactions between, mothers and children: Impacts of maternal and child anxiety. Journal of Abnormal Psychology, 113(3), 471476. doi:10.1037/0021-843x.113.3.471 
Murray, L., Cooper, P., Creswell, C., Schofield, E., \& Sack, C. (2007). The effects of maternal social phobia on mother-infant interactions and infant social responsiveness. . Journal of Child Psychology and Psychiatry, 48(1), 45-52.

Murray, L., Creswell, C., \& Cooper, P. J. (2009). The development of anxiety disorders in childhood: an integrative review. . Psychological Medicine, 39, 1413-1423.

Murray, L., De Rosnay, M., Pearson, J., Bergerin, C., Schofield, E., Royal-Lawson, M., \& Cooper, P. J. (2008). Intergenerational transmission of social anxiety: The role of social referencing processes in infancy. . Child Development, 79(4), 1049-1064.

Murray, L., Lau, P. Y., Arteche, A., Creswell, C., Russ, S., Zoppa, L. D., . . Cooper, P. (2012). Parenting by anxious mothers: effects of disorder subtype, context and child characteristics. Journal of Child Psychology and Psychiatry, 53(2), 188-196.

Murray, L., Pella, J., De Pascalis, L., Arteche, A., Pass, L., Percy, R., . . Cooper, P. (in press). Socially anxious mothers' narratives to their children, and their relation to child representations and adjustment. Development and Psychopathology.

Parker, G. (1983). Parental Overprotection: A Risk Factor in Psychosocial Development. New York: Grune and Stratton.

Pass, L., Arteche, A., Cooper, P., Creswell, C., \& Murray, L. (2012). Doll Play narratives about starting school in children of socially anxious mothers, and their relation to subsequent child school-based anxiety. Journal of Abnormal Child Psychology, 40(8), 1375-1384.

Rachman, S. (1990). The determinants and treatment of simple phobias. Advances in Behaviour Research and Therapy, 12(1), 1-30.

Rapee, R. M., \& Heimberg, R. G. (1997). A cognitive-behavioral model of anxiety in social phobia. Behaviour Research and Therapy, 35(8), 741-756. 
Rapee, R. M., \& Spence, S. H. (2004). The etiology of social phobia: Empirical evidence and an initial model. Clinical psychology review, 24(7), 737-767.

Rapee, R. M., \& Szollos, A. A. (2002). Developmental Antecedents of Clinical Anxiety in Children. . Behaviour Change, 19(3), 146-157.

Raudino, A., Murray, L., Turner, C., Tsampala, E., Lis, A., Pascalis, L., \& Cooper, P. J. (2013). Child anxiety and parenting in England and Italy: the moderating role of maternal warmth. Journal of Child Psychology and Psychiatry, 54(12), 1318-1326.

Rosenbaum, J. F., Biederman, J., Hirshfeld-Becker, D. R., Kagan, J., Snidman, N., Friedman, D., .. Faraone, S. V. (2000). A controlled study of behavioral inhibition in children of parents with panic disorder and depression. American Journal of Psychiatry, 157(12), 2002-2010.

Shanahan, L., Copeland, W., Costello, E. J., \& Angold, A. (2008). Specificity of putative psychosocial risk factors for psychiatric disorders in children and adolescents. . Journal of Child Psychology and Psychiatry, 49, 34-42.

Turner, S. M., Beidel, D. C., Roberson-Nay, R., \& Tervo, K. (2003). Parenting behaviors in parents with anxiety disorders. Behaviour Research and Therapy, 41(5), 541-554. doi:10.1016/s0005-7967(02)00028-1

Unnewehr, S., Schneider, S., Florin, I., Margraf, J., \& rgen, u. (1998). Psychopathology in children of patients with panic disorder or animal phobia. Psychopathology, 31(2), 69-84.

Van Der Bruggen, C. O., Stams, G. J. J., \& Bögels, S. M. (2008). Research Review: The relation between child and parent anxiety and parental control: a meta-analytic review. Journal of Child Psychology and Psychiatry, 49(12), 1257-1269. 
Whaley, S. E., Pinto, A., \& Sigman, M. (1999). Characterizing interactions between anxious mothers and their children. Journal of Consulting and Clinical Psychology, 67, 826-836.

Woodruff-Borden, J., Morrow, C., Bourland, S., \& Cambron, S. (2002). The behavior of anxious parents: Examining mechanisms of transmission of anxiety from parent to child. Journal of Clinical Child and Adolescent Psychology, 31(3), 364-374.

doi:10.1207/153744202760082621 
